\title{
Corrigendum: El-beshbeshi et al. Prognostic Significance of Lymph Node Ratio after Cervical Lymph Node Dissection in Head and Neck Squamous Cell Carcinoma. Res Oncol. 2020; 16(1): 22-30.
}

Wafaa El-beshbeshi ${ }^{1}$, Amir M. Zaid 2, Osama Eldamshety ${ }^{2}$, Islam H. Metwally $^{2}$, Entsar Eladl ${ }^{3}$, Engy M. Aboelnaga ${ }^{1}$

1 Department of Clinical Oncology and Nuclear Medicine, Faculty of Medicine, Mansoura University, Mansoura, Egypt; ${ }^{2}$ Department of Surgical Oncology, Oncology Center, Faculty of Medicine, Mansoura University, Mansoura, Egypt; ${ }^{3}$ Department of Pathology, Faculty of Medicine, Mansoura University, Mansoura, Egypt

This corrigendum corrects the name of the $5^{\text {th }}$ author of this article which was misspelled in the original version as "Entesar Aladl". The correct spelling is "Entsar Eladl". The corrected version of the article replaces the primarily published one. 